\title{
Evoluçáo Funcional e do Equilíbrio em um Paciente com Miotonia de Thomsen: Relato de Caso
}

\author{
Functional Profile and Physical Therapy Treatment in Patient with Thomsen's Myotonia
}

\author{
Sandra Maria Alvarenga Anti Pompeu ${ }^{1}$, José Eduardo Pompeu², Edna \\ Kunimura ${ }^{3}$, Lara Quartier ${ }^{3}$
}

\section{RESUMO}

Introduçáo. A Miotonia de Thomsen é a mais rara das miotonias congênitas. Acomete um a cada 50.000 indivíduos e apresenta padrão de herança autossômica dominante. É caracterizada pela contração muscular duradoura que ocorre após toda contração voluntária. O relaxamento muscular demora para acontecer ou até mesmo não ocorre. Objetivo. verificar a influência do tratamento fisioterápico na funcionalidade e equilíbrio de um indivíduo com Miotonia de Thomsen. Método. Foi realizado um estudo de caso, no qual foram avaliados o equilíbrio e a funcionalidade antes e após o tratamento fisioterápico. Os instrumentos de avaliação utilizados foram: escala de equilíbrio de Berg (EEB), Timed Up and Go (TUG) e Medida de Independência Funcional (MIF). O tratamento consistiu em treino de marcha, equilíbrio com estabilização rítmica, segmentação de atividades funcionais com o auxílio de pistas externas auditivas e referências externas visuais, pelo período de dois meses consistindo em 14 sessóes. Resultados. Foi observado aumento na pontuação da EEB e diminuição no tempo de execução da TUG após tratamento. A MIF não apresentou diferença nos resultados pré e pós-tratamento, uma vez que o paciente era independente funcionalmente na avaliação pré tratamento. Conclusáo. A série de exercícios realizados durante o tratamento mostrou-se eficaz para a melhora do desempenho do equilíbrio e da marcha do paciente estudado.

Unitermos. Miotonia Congênita, Fisioterapia, Reabilitação.

Citaçáo. Pompeu SMAA, Pompeu JE, Kunimura E, Quartier L. Evolução Funcional e do Equilíbrio em um Paciente com Miotonia de Thomsen: Relato de Caso.

\begin{abstract}
Introduction. Thomsen's Myotonia is the rarest of congenital myotonias. It affects one in 50,000 individuals and shows a pattern of autosomal dominant inheritance. It is characterized by sustained muscle contraction that occurs after every voluntary contraction. Muscle relaxation delay to happen or even does not occur. Objective. Check the influence of physical therapy on balance and functionality an individual with Thomsen's Myotonia. Method. It was performed a case report, which was evaluated the balance and functionality before and after physiotherapy treatment. The instruments used were: the Berg Balance Scale (BBS), Timed Up and Go (TUG) and Functional Independence Measure (FIM). The treatment consisted of gait training, balance with rhythmic stabilization, segmentation of functional activities with the assistance of external auditory cues and visual references. Results. There was an increase in score of BBS and a decrease in time execution of the TUG after treatment. MIF showed no difference in results before and after treatment. Conclusion. A series of exercises performed during the treatment was effective for improving balance and gait performance of patient.
\end{abstract}

Keywords. Myotonia Congenita, Physical Therapy, Rehabilitation.

Citation. Pompeu SMAA, Pompeu JE, Kunimura E, Quartier L. Functional Profile and Physical Therapy Treatment in Patient with Thomsen's Myotonia.
Trabalho realizado no Centro Universitário Sáo Camilo, Sáo Paulo-SP, Brasil.

1.Fisioterapeuta, Especialista em Fisioterapia Neurológica pela Universidade de São Paulo (USP), Mestranda em Neurociências e Comportamento - USP, Docente do Centro Universitário São Camilo, São Paulo-SP, Brasil.

2.Fisioterapeuta, Doutorando em Neurociências e Comportamento - USP, Docente do Centro Universitário São Camilo, São Paulo-SP, Brasil.

3.Fisioterapeuta formada pelo Centro Universitário São Camilo, São Paulo-SP, Brasil.
Endereço para correspondência: Sandra Maria AA Pompeu Rua Lino Coutinho 75, apto 41 Bloco A, Ipiranga CEP 04207-000, São Paulo-SP, Brasil.

E-mail: sandraanti@hotmail.com

Relato de Caso Recebido em: 28/02/11 Aceito em: 03/06/11 Conflito de interesses: não 


\section{INTRODUÇÃO}

As distrofias musculares constituem um grupo de doenças genéticas que se caracterizam por fraqueza muscular progressiva, decorrente da degeneração irreversível do tecido muscular esquelético ${ }^{1}$. Essas patologias diferem entre si quanto ao tipo de musculatura atingida, a forma de herança, a idade de início e o quadro evolutivo ${ }^{2}$. A miotomia é definida como uma contração muscular duradoura resultante da diminuição da velocidade de relaxamento do músculo, causando dificuldade no relaxamento muscular após contração voluntária, estímulo mecânico ou estimulação elétrica ${ }^{3,4}$.

As miotonias podem ser hereditárias ou adquiridas $^{3}$. As miotonias hereditárias são formadas por dois grandes grupos, o primeiro está associado à distrofia muscular e tem como protótipo a distrofia miotônica de Steinert. O segundo grupo reune as miotonias hereditárias não distróficas, ou seja, as miotonias congênitas, as paralisias periódicas, a paramiotonia congênita e a miotonia condrodistrófica ou doença de Schwartz-Jampel.

A miotonia congênita é uma doença muscular hereditária, caracterizada eletrofisiologicamente por constante excitabilidade da fibra muscular, que se reflete em miotonia clínica, além da rigidez e hipertrofia muscular 5 .

O fenótipo clínico depende, se o padrão de herança tem característica autossômica dominante ou recessiva, designadas como miotonia generalizada de Thomsen e Becker respectivamente. As duas doenças diferem clinicamente na idade da manifestação, porém os dois casos se associam com mutaçôes no gene do canal de cloro do músculo esquelético (CLCNI) localizado na região do cromossomo sete $\mathrm{q} 35^{2,5,6}$.

A Miotonia de Thomsen (MT) é caracterizada por uma contração muscular duradoura associada a qualquer ação motora voluntária, com retardo no relaxamento muscular, geralmente acompanhado por uma hipertrofia muscular generalizada ${ }^{4}$. Ela caracteriza-se por ser uma doença hereditária de caráter autossômico dominante, com a mutação do gene que codifica o canal de cloro do músculo esquelético, levando a diminuição da condutância ao ín cloro da membrana das fibras musculares e despolarização repetida ${ }^{3,5}$.

Esta forma de miotonia frequentemente se manifesta nos primeiros anos de vida, entre um a dez anos de idade (média de cinco anos) ${ }^{3}$, observando-se alteraçóes na marcha ou ao subir uma escada ${ }^{4}$.

Devido ao quadro motor precoce, associado a fraqueza muscular e fenômeno miotônico, os indivíduos acometidos necessitam de reabilitação motora constante. Porém, não há pesquisas científicas em relação ao tratamento fisioterápico e apenas medicamentoso.

O objetivo deste estudo foi verificar a influência do tratamento fisioterápico na funcionalidade e equilíbrio de um indivíduo com Miotonia de Thomsen: relato de caso.

\section{MÉTODO}

Trata-se de um relato de caso de um paciente com MT. O estudo obteve aprovação do Comitê de Ética em Pesquisa do Centro Universitário São Camilo sob o protocolo n ${ }^{\circ} 75 / 10$ e foi realizado no Centro de Promoção e Reabilitação em Saúde e Integração Social - PROMOVE São Camilo, Ipiranga, São Paulo.

\section{Relato do caso}

Paciente E.M., sexo masculino, 37 anos, diagnóstico clínico laboratorial confirmado de MT por meio de biópsia muscular realizada em 2004. Além das reaçóes miotônicas presentes a qualquer movimentação voluntária, as principais queixas do sujeito eram: dificuldade para iniciar a troca postural de sedestação para bipedestação, iniciar a marcha e mudar de direção, além de falta de equilíbrio nestas atividades. Foi encaminhado pelo médico responsável ao PROMOVE, onde foram aplicadas as seguintes escalas de avaliação: Escala de Equilíbrio de Berg (EEB), Timed Up and Go (TUG) e Medida de Independência Funcional (MIF) motora. O paciente não apresentava nenhuma outra patologia associada que comprometesse os sistemas nervoso central e periférico ou outros. O programa de tratamento foi aplicado duas vezes por semana, no período de dois meses, sendo constituído por 14 sessóes de 50 minutos de duração. $\mathrm{O}$ treino de Equilíbrio baseou-se em exercícios de estabilização rítmica em sedestação na bola suíça, na postura de ajoelhado e semi-ajoelhado. Nas mesmas posturas foram estimulados tanto os ajustes antecipatórios quanto os compensatórios, com estímulos inesperados. Foi realizado treino de alcance de objetos, com movimentos diagonais associados à movimentos de cabeça, exercícios em padrão diagonal de 
membros inferiores em bipedestação. Foi feito o treino funcional associado a referências externas visuais, auditivas e segmentação de movimentos, como o de rolar, passagem de sedestação para bípede, rodar em volta do próprio eixo, subir e descer escadas. Estes exercícios foram conduzidos devido à diminuição de amplitude axial, de dissociação de cinturas e compensaçôes apresentadas pelo paciente. O treino de marcha foi iniciado em solo estável, evoluindo para subida de rampa. Durante a marcha foram utilizados estímulos externos visuais e auditivos quanto o ritmo da marcha, amplitude das passadas, início e final do percurso. Foi enfatizada também a mudança de direção, ato que necessita de dissociação de cinturas e mobilidade axial. Após as 14 sessóes terapêuticas, o paciente foi novamente submetido a re-avaliação das escalas previamente aplicadas.

\section{RESULTADOS}

$\mathrm{Na}$ avaliação pré-tratamento o escore da EEB foi de 38 pontos, o que denota risco de quedas alto, já que escores abaixo de 36 assinalam risco de quedas de quase $100 \%{ }^{7}$. O tempo dispendido na realização da TUG foi de 22 s, sendo que o tempo normal para a realização da tarefa por adultos saudáveis é de 10 s, mais de 20 s na execução da atividade é um valor indicativo da necessidade de intervenção adequada ${ }^{8}$. A MIF é um instrumento que tem por finalidade avaliar de forma quantitativa a carga de cuidados demandada por uma pessoa adulta com restrições funcionais de origem variada' ${ }^{9}$. Neste estudo foi utilizada apenas a porçấo motora da escala, portanto foram avaliados 13 itens de atividades diárias básicas, com pontuaçấo 66 dos 78 pontos possíveis. Em todos os itens da MIF motora o paciente obteve pontuação cinco ou seis, isto é, necessitava de supervisão ou realizava suas atividades com independência modificada, que é a necessidade de alguém próximo para a realização da tarefa.

Após o treinamento houve aumento da pontuação da EEB para 56, máximo de pontos que podem ser obtidos por esta escala. Na TUG, o tempo de execução do trajeto reduziu para 7s. A MIF não apresentou diferença nos resultados pré e pós-tratamento, permanecendo com pontuaçẫo seis para todos os itens motores, totalizando 66 pontos.

\section{DISCUSSÃO}

Os pacientes acometidos relatam lentificação dos movimentos voluntários, perda de agilidade e desequilíbrios constantes, devido a estado de contração não permitir a seleção adequada das sinergias musculares ativas e das que devem ser inibidas visando o movimento funcional e harmonioso.

$\mathrm{Na}$ literatura não existem estudos que descrevam um tratamento cinesioterápico para a MT direcionado às possíveis limitaçôes decorrentes. No único estudo existente, os pesquisadores tiveram como objetivo elaborar um tratamento fisioterápico para a MT combinando a eletroforese com as medicaçôes (benzogexoni e hidroxibutirato de sódio). Este tratamento foi empregado em 34 pacientes com MT e Atrofia Miotônica, comparando os resultados com os alcançados por um grupo composto por 30 pacientes com miotonia tratados por métodos fisioterápicos tradicionais, porém não há a descrição sobre o que foi denominado de método tradicional de tratamento. Como resultados, a eletromiografia de superfície mostrou diminuição de reaçóes miotônicas em 72\% dos pacientes, a eletroneuromiografia aumento da velocidade de condução das fibras nervosas motoras das extremidades em $64 \%$ dos pacientes, enquanto que os métodos tradicionais de tratamento fisioterápico obtiveram diminuição de $20 \%$ e aumento da velocidade na ordem de $25 \%$. Os autores relacionam a melhora dos índices ao bloqueio muscular causado, porém com pouca discussão sobre os resultados atingidos ${ }^{10}$.

O paciente deste estudo apresentava quadro de miotonia global e queixa de dificuldade para iniciar o movimento de sedestação para bípede, iniciar a marcha e para mudar de direção, além de falta de equilíbrio nestas atividades.

A intervenção fisioterápica programada para o paciente baseou-se inteiramente nas queixas citadas, levando em consideração as características próprias da patologia. Foi enfatizado o treino de equilíbrio, treino de segmentação de atividades funcionais associado a referências externas e ritmo, treino de marcha.

O equilíbrio consiste na capacidade de manter o centro de gravidade dentro da base de suporte, com intuito de proporcionar estabilidade durante situaçóes 
estáticas e dinâmicas. O controle postural requer a integração de informaçóes sensoriais para detectar a posição do corpo e movimentos do corpo no espaço, associado à produção de força muscular adequada para compensar os deslocamentos do centro de gravidade ${ }^{11,12}$.

O controle postural adequado depende de características musculares intrínsecas em conjunto com componente neural de ativação ${ }^{12}$. No indivíduo com MT, o componente neural está íntegro enquanto o efetor está alterado devido à excitabilidade da fibra muscular. Assim, apesar da sinalização sensorial ocorrer, a resposta motora é desencadeada de forma lentificada, prejudicando o equilíbrio.

Inicialmente, na $\mathrm{EEB}^{7}$ o paciente apresentava pontuação um em itens como permanecer em apoio unipodal, demonstrando incapacidade em permanecer por três segundos na posição e dois pontos na transferência da posição sentada para em pé, onde ele era capaz de levantarse utilizando as mãos após várias tentativas.

O treino de equilíbrio baseou-se em exercícios de estabilização rítmica, manutenção de diferentes posturas com diversas demandas posturais associados à estimulação de ajustes antecipatórios e compensatórios.

A pontuação da MIF motora manteve-se inalterada, pois a pontuação 66 já indicava que o paciente era independente funcionalmente, demonstrando que apesar da miotonia o paciente utiliza compensaçôes e adaptações nas açôes rotineiras, pois a MIF não classifica a qualidade da função, apenas a necessidade ou não de terceiros.

$\mathrm{O}$ indivíduo para exercer plenamente suas AVDs e manter-se, dessa forma, independente, necessita de um bom desempenho físico-funcional. O programa proposto mostrou-se eficaz para o paciente acompanhado, sugerindo que atividades como caminhar, subir e descer escadas, levantar-se da cama ou de uma cadeira tornaram-se mais eficazes.

\section{CONCLUSÃO}

A série de exercícios propostos mostrou-se eficaz para a melhora do desempenho da marcha e do equilíbrio do paciente com MT estudado. O paciente apresentavase independente funcionalmente, porém utilizava estratégias compensatórias para a realização das atividades diárias. Os resultados sugerem que a fisioterapia pode contribuir para a recuperação das alteraçôes motoras decorrentes da MT.

\section{REFERÊNCIAS}

1.Morales F, Cuenca P, Valle G, Brian R, Sittenfeld M, Montoya O, et al. Miotonía congénita: caracterización clínica de una familia costarricense afectada por la enfermedad de Thomsen. Neuroeje 2003;17:82-6.

2.Grippo J, Grippo T. Canalopatías em neurologia. Rev Neurol 2001;33:643-7. 3.Azevedo HCA, Mendonça LIZ, Salum PNB, Carvalho MS, Nagahashi-Marie SK, Siqueira-Carvalho AA, et al. Miotonia congênita: relato de sete pacientes. Arq Neuro-psiquiatr 1996;54:595-600.

http://dx.doi.org/10.1590/S0004-282X1996000400008

4.Jiménez O, José JS, Santos M. Miotonia congênita de Thomsen. A proposito de un caso. Acta. Méd Domin 1990;12:220-2.

5.Otsuka MA, Boffa CFB, Vieira ABAM. Distrofias musculares: fisioterapia aplicada. Rio de Janeiro: Revinter, 2005, 247p.

6.Garcia A, Armas M, Marrero M. Síndrome de Steinert-Curschmann. Protocolo de fisioterapia em las afecciones neonatales y descripción de cinco casos clínicos. Fisioterapia 2003;25:110-20.

7.Miyamoto ST, Lombardi Jr I, Berg KO, Ramos LR, Natour J. Brazilian version of the Berg balance scale. Braz J Med Biol Res 2004;37:1411-21.

http://dx.doi.org/10.1590/S0100-879X2004000900017

8.Podsiadlo D, Richardson S. The timed "Up \& Go": a test of basic functional mobility for frail elderly persons. J Am Geriatr Soc 1991;39:142-8.

9.Riberto M, Miyazaki MH, Jucá SSH, Sakamoto H, Pinto PPN, Battistella LR. Validação da Versão Brasileira da Medida de Independência Funcional. Acta Fisiatr 2004;11:72-6.

10.Lobzin VA, Saikova LA, Shiman AG, Pustozerova VG. Physiotherapy methods in the correction of myotonic disordens. Vopr Kuroltol Fizioter Lech Fiz Kult 1990;53:53-4.

11.Faria, JC, Machala CC, Dias RC, Dias JMD. Importância do treinamento de força na reabilitação da função muscular, equilíbrio e mobilidade de idosos. Acta Fisiatr 2003;10:133-7.

12.Shumway-Cook A, Woollacott M. Controle Motor: Teoria e aplicaçóes práticas, $3^{a}$ ed. São Paulo: Manole, 2003, 610p. 